\title{
The invariance of market innovation to the number of firms
}

\author{
Raaj Kumar Sah* \\ and \\ Joseph E. Stiglitz**
}

This article provides a set of conditions under which the $R \& D$ undertaken in a market economy is invariant to the number (or size distribution) of firms and the market's allocation is efficient (i.e., given the aggregate expenditure, the market chooses socially optimal projects). As in several patent race studies, we assume that a "winner-takes-all" competition determines firms' gains, but our model differs from earlier studies in that firms are not restricted to undertake only one research project. Our analysis shows that how one characterizes a firm's choices (and innovation technologies) has a strong influence on the conclusions one draws from economic analyses of $R \& D$.

\section{Introduction}

- A major concern of the recent research in the theory of innovation has been the effect of market structure on private marginal returns to firms from innovations, and, thus, on the equilibrium level of R\&D undertaken in a market economy. Recent work has also emphasized the relationship between marginal private returns and social returns which, in general, may not be the same (Barzel, 1968; Dasgupta and Stiglitz, 1980; Kamien and Schwartz, 1982; Loury, 1979; Stiglitz, 1986). For instance, in some patent races the private return is either zero, when the firm is not first to invent, or the total appropriable return, when the firm is first to invent, while the social return is the increase in the present value of societal gain from having the invention earlier than it otherwise would have been available.

The present analysis is based on a model in which the gains to firms are determined in a market characterized by Bertrand competition. This assumption gives our model a "winner-takes-all" feature similar to that in the patent race literature. There is a private return to innovation only when a single firm innovates; when two (or more) firms innovate, Bertrand competition means that they earn no profits. In contrast to earlier work, however, we posit that a firm is not restricted to undertaking only one research project, and that it may undertake more than one project aimed at the same innovation if it is profitable to do

* Yale University.

** Princeton University.

We thank the Editorial Board and three anonymous referees for their valuable comments on earlier versions of this article. 
so. In other words, a firm determines not only the expenditure (or effort) on any particular R\&D project it undertakes, but also the number of different projects it will pursue.

Our strongest results follow directly and intuitively from these assumptions. We show that the marginal private value of an incremental project (or of incremental expenditure on different projects) does not depend on market structure. The reason is simple. A project yields a payoff to a firm only when it is the only successful project. If another firm's project succeeds, the Bertrand competition eliminates all rents. If another project of the same firm succeeds, the incremental return to the project under consideration is also zero.

The implications of this result are powerful. The most important of them are the following.

(1) The market portfolio of projects-the number of projects undertaken as well as the expenditures on each of them-is unaffected by the number of firms. This result, which we call the "strong invariance result," follows from the earlier observation that the marginal decisions concerning research projects are not influenced by the number of firms. The strong invariance result obviously implies that the number of firms has no effect on the pace of innovation in a market economy. We refer to this as the "weak invariance result." These conclusions are in marked contrast with some previous studies that have found the number of firms to be a critical determinant of innovation in a market economy (Barzel, 1968; Dasgupta and Stiglitz, 1980; Kamien and Schwartz, 1982; Loury, 1979; Stiglitz, 1986).

(2) The market equilibrium is "efficient" in the sense that the market porfolio of projects maximizes the economywide probability of a successful innovation, given the total level of expenditure on R\&D. But the market expenditure on $R \& D$ is smaller than the socially optimal level.

These results are fairly general. They hold, for instance, whether research projects have independent outcomes or not, whether there is symmetric equilibrium or not, and whether there is a single technology or several different technologies for innovation. In a more restricted model we also establish the following results.

(3) The intensity at which a research project is pursued in the market is invariant to the magnitude of appropriable rent from successful innovation. If the rent is larger, then the number of projects undertaken is larger.

(4) The intensity with which a project is undertaken in the market is socially optimal, but, in general, the market undertakes fewer projects than is socially desirable.

(5) The number of firms in the market affects the division of gains from innovation between firms and consumers, and, thus, it affects aggregate social gains. A larger number of firms lowers industry's expected profit as well as the expected profit of an individual firm. Also, for a class of innovations, a larger number of firms raises consumers' gains as well as the aggregate social gains from innovation.

For brevity in presentation we develop the above results by using a highly simplified formal model. The first two results stated above, however, can be generalized in a number of ways that we identify. In the concluding section we review the central assumptions underlying the strong invariance result, and summarize the main implications that this article might have for economic analysis of R\&D.

\section{The model and results}

- A research project has a binary outcome: it is either successful or not. ${ }^{1}$ If $e$ is the (variable) expenditure on a research project, then the probability of its success is $p(e)$, where

\footnotetext{
${ }^{1}$ Here we abstract from issues concerning the timing and the scale of innovations; that is, by spending more resources one can alter the date of innovation or the magnitude of rent. We discuss these aspects in the last section.
} 
$p_{e} \equiv \partial p(e) / \partial e>0$ and $1>p>0$ when $e$ is positive but finite. At present we assume that the outcomes of different projects are independent of one another, regardless of firm affiliation. A firm can undertake as many projects as it desires, all of which are aimed at the same innovation. Thus, if $e_{i j}$ denotes the expenditure by the $i$ th firm on its project $j$, and if this firm undertakes $j=1, \ldots, k_{i}$ projects, then the probability that at least one of the projects undertaken by this firm is successful is given by $q_{i}=1-\prod_{j=1}^{k_{i}}\left(1-p\left(e_{i j}\right)\right) .^{2}$

The gains to firms are determined in a Bertrand market competition. Specifically, the (positive) rent gained by a firm is $R$ if it innovates and if no other firm innovates. If two or more firms innovate, then none of them gets any rent, and the benefits of innovation accrue solely to consumers. We denote by $h_{i}$ the probability that all firms other than the $i$ th firm

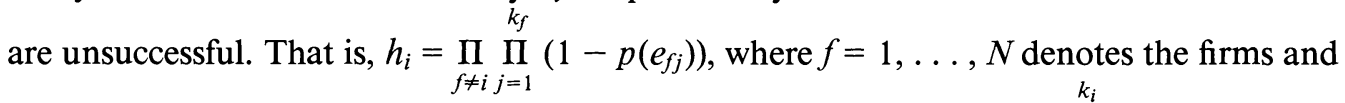
$N \geq 1$ and is finite. Then the (expected) profit of firm $i$ is $\pi_{i}=R h_{i} q_{i}-\sum_{j=1}^{k_{i}}\left(e_{i j}+a\right)$, where
$a$ is the fixed cost of undertaking a project.

We focus on a symmetric interior Nash equilibrium in which all projects have the same $p(e)$ function, each firm undertakes the same number of projects, and, further, if a firm undertakes more than one project, then all projects are undertaken at the same level of expenditure. ${ }^{3}$ At an interior equilibrium $e>0, k \geq 1$, and both $e$ and $k$ are finite. Therefore,

and

$$
q=1-(1-p(e))^{k}
$$

$$
h=(1-p(e))^{N k-k} \text {. }
$$

If $q(k)$ denotes a reduced-form representation of (1), then the first-order conditions with respect to $e$ and $k$ for a firm's optimum are $R h q_{e}-k=0$ and $R h[q(k)-q(k-1)]$ $-(e+a)=0$, respectively. ${ }^{4}$ Using (1) and (2), we can restate these equilibrium conditions as

and

$$
R(1-p)^{n-1} p_{e}=1
$$

$$
R(1-p)^{n-1} p=e+a
$$

where $n=N k$ is the total number of projects undertaken in the market.

$\square$ Strong invariance result. Note that the above expressions determine the expenditure per project, $e$, and the total number, $n$, of projects undertaken in the market. A change in the number of firms, $N$, simply changes $k$ and leaves $n$ and $e$ unchanged. Thus, the only effect of $N$ is on the number of projects a firm undertakes, which is $k=n / N$. In a duopoly, for instance, each of two firms undertakes half as many projects as a monopoly would have undertaken. It follows, then, that the number of firms in the market has no impact on the total number of research projects undertaken and the intensity of each of the projects.

\footnotetext{
${ }^{2}$ Note that we are not assuming constant returns to scale, because the aggregate success probability (that is, the probability of at least one successful project among a set of projects) does not, in general, increase in proportion to the number of projects undertaken. In fact, when all projects have the same expenditure level, $e$, the "production function" giving the aggregate success probability as a function of total expenditure on research, $E$, is $q=1-(1$ $-p(e))^{E /(e+a)}$, where $a$ is the fixed cost per project.

${ }^{3}$ As is well known, there may not always exist a symmetric interior Nash equilibrium, for instance, because of the nonconcavity of the relevant functions. Also, we are assuming that there are no binding constraints (such as the constraint on credit) that might prevent a firm from undertaking the desired set of projects. We discuss a more general framework later.

${ }^{4}$ For simplicity, we have used an equality to represent the optimality with respect to $k$. A more general expression is $R h[q(k)-q(k-1)] \geq(e+a)>R h[q(k+1)-q(k)]$. This does not affect the invariance result derived below.
} 
Further, let $z$ denote the aggregate probability of innovation in the market, that is, the probability that at least one of the projects in the market portfolio is successful. Then

$$
z=1-(1-p)^{n} \text {. }
$$

It is obvious that this probability, which in the present simple model represents the market's pace of innovation, is also invariant to the number of firms.

We briefly mentioned the intuition behind the strong invariance result in the Introduction. Consider the marginal decision of a firm to undertake the last project (or to invest the last dollar on a project). This project (or dollar) yields a benefit only if the other projects undertaken by this firm fail, as well as if all of the projects undertaken by other firms fail. The marginal decisions are thus influenced by the total number of projects undertaken in the market and not by how these projects are partitioned between the firm making the decision and the other firms.

Though we have used a highly simplified model in the above analysis, the strong invariance result is more general. In particular, it does not depend on whether the outcomes of projects within or across firms are statistically independent, whether there is a single technology or many technologies for innovation, and whether the equilibrium is symmetric or asymmetric. ${ }^{5}$

The qualitative reason underlying these generalizations can be seen easily in the matrix in Table 1, which shows the incremental gain to firm $f$ from undertaking a particular project at some level of expenditure. It is clear that whether the firm undertakes this project depends only on the probability that the outcome will be in the northeast quadrant of the matrix (for brevity, we call this the "incremental probability of success"), and that probabilities of other outcomes are inconsequential because there is zero gain under these other outcomes. It is also clear that the incremental probability of success does not depend on how the projects already accepted are partitioned among firms. The same logic applies to the marginal decisions of every firm, and the logic is valid regardless of the nature of statistical dependence among projects or the symmetry or asymmetry within or across firms' portfolios of projects.

To see the same argument formally, let $r_{j}$ denote the probability that a project with expenditure $e_{j}$ succeeds while all other projects in the economy fail. Then this project will be undertaken if

and it will not be undertaken if

$$
R r_{j} \geq e_{j}
$$

$$
R r_{j}<e_{j}
$$

Now, since the partitioning of projects among firms does not alter $r_{j}$ 's, the number of firms in the economy does not influence the conditions, (6) and (7), characterizing the market equilibrium. Thus, it follows directly that the market portfolio is invariant to the number of firms.

Furthermore, the economic content of the strong invariance result is readily extended to the cases where there are multiple equilibria. Specifically, if $A$ and $A^{\prime}$ are two market

TABLE 1 Incremental Gain to Firm $f$ from Undertaking a Particular Project

\begin{tabular}{lcc}
\hline & $\begin{array}{c}\text { All Other Projects } \\
\text { of Firm } f \text { Fail }\end{array}$ & $\begin{array}{c}\text { Any Other Project } \\
\text { of Firm } f \text { Succeeds }\end{array}$ \\
\hline All Projects at All Other Firms Fail & $R$ & 0 \\
Any Project at Any Other Firm Succeeds & 0 & 0 \\
\hline
\end{tabular}

${ }^{5}$ In the asymmetric case not only can a firm undertake a set of dissimilar projects, but the project portfolios of different firms can also be dissimilar. 
economies with a different number of firms, and if we consider any one of the many equilibria that economy $A$ can sustain, then this equilibrium project portfolio is also sustainable in economy $A^{\prime}$. Moreover, this result is also unaltered if different firms have access to different subsets of the economywide set of technologies, provided the same type of firms is in both economies (though the numbers of firms of different types are different between $A$ and $\left.A^{\prime}\right)^{6}$

We should emphasize here that the strong invariance result does require the equilibria under consideration to be interior; that is, the firms' choices in an equilibrium are not determined by reasons other than profitability. An equilibrium is not interior if firms face constraints on the number of projects (of the technologies to which they have access) they can undertake and if, because of this constraint, one or more firms undertake fewer projects than they would have otherwise undertaken. The reason is intuitive. If one firm undertakes one or more projects at inefficient levels because of the constraints it faces, then it may lead some other firms to undertake projects at inefficient levels, because the marginal gains to these firms are influenced by what is undertaken in the market.

The preceding comment suggests another useful observation. As we mentioned earlier, conventional analyses of $\mathrm{R} \& \mathrm{D}$ have typically restricted a firm to undertaking only one project. Such a specification implies in our model that the firms' choices have been forced not to be interior. The resulting inefficient equilibrium in R\&D is not surprisingly sensitive to the number of firms. This can be seen in our basic model by noting from (3) that if $k$ is exogenously fixed at unity, then the expenditure per project-and hence the economywide probability of innovation, given by $z$ in (5)-depend, in general, on the number of firms. But such a dependence of R\&D on market structure could be viewed as nothing more than an artifact of the arbitrary specification of firms' choices and research technologies.

$\square$ Other characteristics of market portfolio. Reverting to our simple model, we obtain the following from expressions (3) and (4):

$$
p_{e}(e)=p(e) /(e+a) \text {. }
$$

This shows that in market equilibrium the marginal increase (by spending an extra dollar) in the success probability of a project is equal to the average (per dollar) probability of success. This is exactly what one would expect, because in our model a firm chooses not only how much it will spend on a project, but also how many projects it will undertake. An immediate consequence of (8) is that the expenditure per project is independent of the rent from successful innovation.

It is important to note here that the assumptions of a symmetric equilibrium and of a statistical independence among the outcomes of projects are crucial to this result as well as to other results derived below, except those noted otherwise. To see this consider a project with expenditure $e_{j}$ that has been undertaken on the margin, and let $\eta_{j}$ denote the probability that all other projects fail. Then the expressions analogous to (3) and (4) are $R \eta_{j} p_{e}\left(e_{j}\right)=1$, and $R \eta_{j} p\left(e_{j}\right)=e_{j}+a$. These yield $p_{e}\left(e_{j}\right)=p\left(e_{j}\right) /\left(e_{j}+a\right)$. It follows, then, that (8) must hold in a symmetric equilibrium because in this case all projects are identical as well as marginal.

The above result can be easily extended to the case in which there are several alternative technologies of innovation. Let the superscript $T$ denote different technologies. Thus, for a project using technology $T, a^{T}$ denotes the fixed cost, and $p^{T}\left(e^{T}\right)$ denotes the probability of success when the expenditure is $e^{T}$. Analogous to (8), then, the condition $p_{e}^{T}\left(e^{T}\right)=p^{T}\left(e^{T}\right) /\left(e^{T}+a^{T}\right)$ would hold for each technology that is used in equilibrium. The preceding condition not only indicates the independence of project size (of a given technology) to the rent $R$, but also provides the equilibrium relationship among the levels of expenditure on the projects using different technologies.

\footnotetext{
${ }^{6}$ For a derivation of these results, see a more detailed version (1986) of this article.
} 
Finally, by perturbing (3) with respect to $R$, and noting that $e$ is invariant to this perturbation, we obtain

$$
d n / d R=-1 / R \ln (1-p)>0 .
$$

Thus, as one would expect, a larger number of projects is undertaken in the market if the rent from innovation is larger.

Welfare analysis of market portfolio. The strong invariance results we have derived above might give an impression that the number of firms as well as the public policy that might affect this number has no role to play in the context of research and innovation. This is not correct because although the number of firms does not affect the aggregate probability of innovation, it does affect the division of this probability between the case when only one firm innovates and the case when more than one firm innovates. Since the postinnovation gains to consumers (or firms) are different under these two cases, their expected gains are affected by the number of firms.

To see this, note that $N h q$ represents the probability that only one firm innovates, and recall that $z$, given in (5), denotes the aggregate probability of innovation in the market. Therefore, if $g$ denotes the probability that two or more firms innovate, then

$$
g=z-N h q \text {. }
$$

Our earlier analysis has shown that $z$ is independent of $N$. Thus, it follows that the division of $z$ between $g$ and $N h q$ is not independent of $N$, because ${ }^{7}$

$$
d(N h q) / d N=h[k \ln (1-p)+q]<0 .
$$

This is what we would expect: if the same number of projects is divided among a larger number of firms, then the probability that two or more firms will innovate is higher, and, correspondingly, the probability that only one firm will innovate is lower.

The above reasoning also suggests that a larger number of firms would lower the aggregate profit of firms. This can be ascertained as follows. The aggregate profit is

$$
N \pi=R N h q-n(e+a) .
$$

Note that the second term in the right-hand side of (12) does not depend on $N$. But, from (11), the first term is decreasing in $N$. Thus, $d(N \pi) / d N<0$. Further,

$$
d \pi / d N=[d(N \pi) / d N-\pi] / N<0,
$$

if a firm's profit is nonnegative, as we assume. Therefore, a larger number of firms lowers the profit for a single firm as well as for the economy as a whole.

Next consider consumers. They face a monopoly on the fruits of innovation if only one firm innovates, but get the entire benefit from innovation if two or more firms innovate. If their gains in these two cases are represented by $S_{1}$ and $S_{2}$, respectively, then $S_{2}-S_{1}$ represents the loss due to monopoly, relative to the case when consumers receive the full benefit of innovation. Normally, $S_{2}-S_{1}$ will be positive. ${ }^{8}$ Now, the expected gain to consumers is $S=S_{1} N h q+S_{2} g$. Thus, using (10), we can restate $S$ as

$$
S=S_{2} z-\left(S_{2}-S_{1}\right) N h q
$$

\footnotetext{
${ }^{7}$ We obtain the sign of $(11)$ as follows. From $(1), q(k)$ is easily seen to be strictly concave in $k$. Thus, $q(k)-q(0)<q_{k}(0) k$. Using (1) again, we obtain $k \ln (1-p)+q(k)<0$. Therefore, (11) is negative.

${ }^{8}$ Consider, for instance, the case of a cost-reducing innovation. Suppose the innovation reduces the fixed unit cost of a product from $c_{0}$ to $c_{2}$, where $c_{0}$ is the current (competitive) price. If only one firm innovates, then it sets a monopoly price $c_{1}$, where $c_{0} \geq c_{1}>c_{2}$. The rent to this firm is $R=\left(c_{1}-c_{2}\right) D\left(c_{1}\right)$, where $D$ is the aggregate demand function. If more than one firm innovates, then-owing to Bertrand competition-the new competitive price is $c_{2}$. Obviously, then, $S_{2}-S_{1}>0$. Also, unless the demand is entirely insensitive to the price, the standard consumers' surplus arguments show that $S_{2}-S_{1}>R$.
} 
where the first term on the right-hand side represents the full gain from innovation and the second term represents the loss due to monopoly. From (11) and (13) it is obvious that the consumers' gain is larger if the number of firms is larger.

Since the number of firms has opposite effects on consumers and firms, we combine these two effects to study the societal implications. Our analysis here assigns equal weights to the gains of consumers and firms, but we can easily rephrase the results if the weights are different. The social gain is $B=S+N \pi$, which, from (12) and (13), can be expressed as

$$
B=S_{2} z-\left(S_{2}-S_{1}-R\right) N h q-n(e+a) .
$$

It is apparent from (11) and (14) that whether the social gain is increasing or decreasing in the number of firms depends on whether the consumers' loss due to monopoly, $\left(S_{2}-S_{1}\right)$, is larger or smaller than the firms' rent from monopoly, $R$. In typical cases consumers suffer deadweight losses when a monopoly captures any rents: $S_{2}-S_{1}>R .{ }^{9}$ In these cases a larger number of firms yields a larger social gain.

The last result also suggests that if the government can alter the number of firms in a nondistortive manner (for instance, through an entry subsidy) and if there are no fixed costs associated with establishing a firm, then the optimal number of firms is such that each firm undertakes a single project. Obviously, if there are fixed costs, we can use (14) to calculate the corresponding optimal number of firms. ${ }^{10}$

Comparison between market portfolio and social optimum. Our objective here is to contrast the socially optimal resource allocation to $R \& D$ with the market allocation we described. Let $n$ denote the number of projects undertaken by the planner. Then $z$, given in (5), is the probability that at least one project is successful, in which case consumers receive the full benefits of innovation. The expected social gain is $S_{2} z-n(e+a) .{ }^{11}$ The corresponding first-order conditions, with respect to $e$ and $n$, characterizing an interior optimum, are

$$
S_{2}(1-p)^{n-1} p_{e}=1
$$

and

$$
S_{2}(1-p)^{n-1} p=e+a .
$$

Note the similarity between the social allocation described above, and the market equilibrium described by (3) and (4). The two sets of expressions are identical except that the gain from successful innovation is $R$ for a firm, whereas it is $S_{2}$ for the planner. This similarity should not be surprising because, once again, the marginal decision of the planner (to undertake the last project, or to invest the last dollar on a project) depends on the total number of projects that have already been undertaken, just as it did for a firm in the market. Now, recall that $d e / d R=0$. It follows then that the market expenditure per project is at the socially efficient level. An immediate consequence of the above result is that the planner would select exactly the portfolio of research projects that a market does if he were constrained to spend no more than what the market spends. In this sense the market portfolio of projects is "efficient."

\footnotetext{
${ }^{9}$ See footnote 8 .

${ }^{10}$ Naturally, these conclusions do not extend to distortive instruments such as investment tax credits. Also, certain instruments of policy may not be feasible owing to informational problems. For example, it may be difficult to monitor the number of projects a firm undertakes.

${ }^{11}$ As in some earlier literature (Dasgupta and Stiglitz, 1980), the present treatment of the social optimum assumes that the revenue required to finance the $R \& D$ can be raised in a nondistortive manner. If only distortive instruments (such as commodity taxes) are available for raising revenue, then under some circumstances the welfare consequence of the market allocation may not be significantly different from that of the social optimum. See Stiglitz (1986).
} 
Next, recalling (9), we see that the similarity between the market equilibrium and the social optimum also implies that whether the number of projects undertaken in the market is smaller (or larger) than the socially optimal number depends on whether $S_{2}$ is larger (or smaller) than $R$. In a wide variety of circumstances (for instance, for innovations dealing with cost reduction), the full consumers' gain from innovation is larger than the rents to a firm from monopolizing the innovation: $S_{2}>R$. In these cases it follows that the market undertakes fewer projects than are socially desirable.

The last two results concerning the market portfolio-that this portfolio is efficient, but that it entails a smaller expenditure than what is socially optimal-can, once again, be shown to be robust to several aspects of the model. In fact, these results are generalizable in the same way we described earlier in the context of the invariance result. To see this let $M_{j}$ represent the number of projects with expenditure $e_{j}$, and let $r\left(M_{1}, M_{2}, \ldots\right)$ denote the probability that at least one project out of an arbitrary portfolio $\left(M_{1}, M_{2}, \ldots\right)$ is successful. Then it is straightforward to verify that if the planner were to maximize $\operatorname{Rr}\left(M_{1}, M_{2}, \ldots\right)$ $-\sum_{j} M_{j} e_{j}$, the optimality conditions for the resulting portfolio are (6) and (7). That is, the optimality conditions are the same as the market equilibrium conditions.

Next, denote the market portfolio by $\left(M_{1}^{*}, M_{2}^{*}, \ldots\right) .{ }^{12}$ Clearly, then, the portfolio $\left(M_{1}^{*}, M_{2}^{*}, \ldots\right)$ maximizes the probability of at least one successful project, $r\left(M_{1}, M_{2}, \ldots\right)$, when the planner can spend no more than $\sum_{j} M_{j}^{*} e_{j}$. It follows, therefore, that the planner will choose the same portfolio, even when he is maximizing $S_{2} r\left(M_{1}, M_{2}, \ldots\right)$, provided he is constrained to spend no more than the expenditure, $\sum_{j} M_{j}^{*} e_{j}$, undertaken by the market. Further, the expenditure of a social planner would exceed $\sum_{j} M_{j}^{*} e_{j}$ if he did not face any constraint on spending. This is so since the social gain from a successful project, $S_{2}$, exceeds $R$. Thus, the market expenditure on R\&D is smaller than what is socially optimal.

\section{Concluding remarks}

- The question of the relationship between market structure and innovation is a central one, both for economic theory and economic policy. A long-standing concern of antitrust policy has been whether lack of competition dampens incentives to innovate. Earlier studies on the relationship between the number of firms and the level of innovation tended to confirm the standard view that competition and the pace of innovation would be positively correlated. ${ }^{13}$ Thus, the absence of any relationship between the two in the present study would appear to be a significant finding. The question is, to what can we attribute the difference between our results and the standard view? What broader implications might our results have for the economic analysis of $\mathrm{R} \& \mathrm{D}$ ?

Before we address these issues, it is important to point out that the particular type of invariance on which the earlier analysis has focused requires each project in the market portfolio of research projects to be unaffected by the number of firms. This is a very "strong" form of invariance indeed, because what is relevant for many critical economic questions (such as the determinants of the pace of innovation in the economy) is not the composition of the market portfolio of projects, but only the economywide probabilities of innovation (represented in our basic model by the probability $z$ ). It is useful, therefore, to distinguish between the strong invariance analyzed earlier and a "weak invariance" that merely requires

\footnotetext{
${ }^{12}$ For brevity, we are assuming here that a unique project portfolio represents the market equilibrium. See Sah and Stiglitz (1986) for an extension to the cases of multiple equilibria.

${ }^{13}$ We are assuming, of course, that the firm could obtain a patent on the innovation. See, for instance, Loury (1979) and Dasgupta and Stiglitz (1980).
} 
the economywide pace of innovation to be not significantly sensitive to the number of firms. Since strong invariance implies weak invariance, but not vice versa, it is obvious that the latter would hold under a wider set of circumstances than those under which the former would hold.

We have emphasized in the last section that the strong invariance result holds in models far more general than the simplified formal model we have used. This result holds, for instance, when there is asymmetric equilibrium, or when there are complex correlations among the outcomes of various projects. We have also emphasized a critical difference between our model, in which firms are not constrained to undertake only one research project, and earlier analyses, in which a firm is assumed to undertake only one project. The existence of a relationship in the latter models between the number of firms and the pace of $R \& D$ can be viewed, in part, as a consequence of the imposed restriction on firms' choices and innovation technologies.

At the same time, certain crucial assumptions are required for the strong invariance result to hold; we discuss here three assumptions that appear to be particularly important. First, we have assumed that the cost of a particular project, or the probabilities of its outcome, are not significantly affected by the "firm affiliation" of the project (that is, which firm undertakes this particular project). Thus, the probability of success of a particular project (conditional, say, on the failure of all other projects) is a function of the expenditure on that project and the expenditures on other projects, but not a function of the firms in which those other projects are undertaken. ${ }^{14}$ Whether this assumption is plausible depends on the nature and organization of a firm.

If the information flows affecting the outcomes of different projects within a firm are markedly different from those across firms (for instance, because the same researchers are involved in more than one project undertaken within a firm), then the firm affiliation of projects may affect the interactions among their outcomes. On the other hand, if different projects within a firm are sufficiently isolated from one another (for instance, because of the need to monitor the performance of different groups of researchers), then the firm affiliation may be less relevant. Clearly, these issues go to the heart of the question of what is a firm, a question that we obviously cannot solve in this brief article.

Analogously, we have assumed that the incremental cost of a particular project with given conditional probabilities of outcomes is not significantly influenced by which other projects the firm has already undertaken. If, on the other hand, there are significant intrafirm cost economies or diseconomies across projects, then economic efficiency will, of course, entail there being an "efficient" number of firms. But in this case a change in the number of firms might affect the pace of innovation not because of the effect on the level of competition, but because of the effect on the costs of undertaking R\&D. Indeed, we conjecture that one could obtain a modified invariance result of the form that, if there were a sufficiently large number of firms capable of undertaking $R \& D$, then the equilibrium pace of innovation would be unaffected by the number of firms, because a subset of firms would be undertaking R\&D at an efficient level.

The second assumption is that every project yields the same rent if it is the "successful" project; that is, the research projects are aimed at specific process innovations or, equivalently, at specific product innovations for perfect substitutes. To see this consider a model where

${ }^{14}$ More precisely, the nature of interactions among the outcomes of a specific set of projects is invariant to how this set of projects is divided among the firms. Thus, for example, if there are three projects, then the probabilities of various outcomes (such as the probability that the first two projects are successful but the third is not) is not significantly affected by whether the same firm undertakes all three projects or three different firms undertake one project each. 
the outcome of a research project (aimed at cost reduction) is a distribution of (unit) costs for producing a particular good. ${ }^{15}$ Let the stochastic variable $c_{j}$ denote the cost attained by project $j$, let $c^{*}$ denote the minimum cost attained by all firms (across all of their projects) excluding the firm (say, firm $f$ ) that is considering whether to undertake project $j$, and let $c^{* *}$ denote the minimum cost attained by all projects in the economy other than project $j$. Thus, $c^{* *}$ is the minimum of the costs attained by firm $f$ on all its projects other than project $j$, as well as the costs attained by other firms on all of their projects. Clearly, $c^{*} \geq c^{* *}$.

Now, if $D(\cdot)$ denotes the aggregate demand for the good as a function of its price, then Bertrand competition implies that the stochastic representation of the incremental gain to firm $f$ from project $j$ is $D\left(c^{*}\right)\left[\operatorname{Max}\left\{0, c^{* *}-c_{j}\right\}\right]{ }^{16}$ It is apparent from the preceding expression that the incremental gain from project $j$ is independent of which firm undertakes project $j$ if (i) there are only two outcomes of a research project ("success" or "failure" in reducing the cost by a specific amount), or (ii) the aggregate demand for the good is not significantly sensitive to price changes in the relevant range (that is, in the range between $c^{*}$ and $c^{* *}$ ). In other cases, which firm undertakes what projects can make a difference to the magnitude of rent from innovation. Similar effects arise within a monopolistically competitive model, where competition is focused on developing new products that are not perfect substitutes for each other.

The third important assumption underlying the strong invariance result is that the project market competition is Bertrand. What is relevant here is the implication of such a competition that the "winner takes all." In Cournot equilibrium, on the other hand, if the innovation is not "large," the winner does not take all. If project $j$ undertaken by firm $f$ is successful, the marginal return to this firm from the success of another project that this firm has undertaken is zero, but the gain to this firm from the success of a project undertaken by some other firm is not zero. Thus, in our model the degree of competition in the product market affects how the benefits of R\&D are split between consumers and producers, but it does not affect the level of R\&D. In a Cournot model, however, both the split of benefits between consumers and producers and the level of R\&D are affected.

We can thus restate our central message as follows. It is not surprising, as the above discussion shows, that there is a range of important circumstances under which the strong invariance result will not hold. What is surprising is that this result holds in as many circumstances as it does. Clearly, then, to analyze innovation in a market economy, we must consider more than the number (or the size distribution) of firms in the market. Indeed, key to ascertaining the effect of market structure on the pace of innovation are an analysis of firms' choices-including the technology of innovation and the intrafirm externalities across different projects and activities undertaken by a firm-and an analysis of how the gains from innovation are divided among competing firms through the competition in product markets. Furthermore, our analysis suggests the need to investigate weaker versions of invariance of economywide innovation to market structure. In other words, what is relevant is not merely to note that in a particular model the aggregate pace of innovation is influenced by the number of firms, but also to determine how significant or insignificant this influence is, and what specific features of the economy contribute to the significance of such an influence.

\footnotetext{
${ }^{15}$ Obviously, the only relevant outcomes are those under which the cost is smaller than the current cost.

${ }^{16}$ Bertrand competition means here that when a project of firm $f$ yields the lowest cost in the economy, then this firm becomes a monopolist, and it sets the price of the product at a level infinitesimally smaller than $c^{*}$, which is the lowest cost achieved by all other firms. The case where the monopolist chooses to set a price between $c^{*}$ and $c^{* *}$ is analogous.
} 


\section{References}

BARZEL, Y. “Optimal Timing of Innovation.” Review of Economic Studies, Vol. 35 (1968), pp. 348-355.

DASGUPTA, P. AND STIGLITZ, J.E. "Industrial Structure and the Nature of Innovative Activity." Economic Journal, Vol. 90 (1980), pp. 266-293.

Kamien, M.I. AND SCHWARTz, N.L. Market Structure and Innovation. Cambridge: Cambridge University Press, 1982.

LOURY, G.C. “Market Structure and Innovation.” Quarterly Journal of Economics, Vol. 93 (1979), pp. 395-410.

SAH, R.K. AND STIGLITZ, J.E. "The Invariance of R\&D to the Number of Firms in the Industry." Working Paper No. 1798, National Bureau of Economic Research, Cambridge, 1986.

STIGLITZ, J.E. "Theory of Competition, Incentive and Risk" in J.E. Stiglitz and G.F. Mathewson, eds., New Developments in the Analysis of Market Structure, Cambridge: MIT Press, 1986, pp. 399-446. 